\title{
A Medical Student's Surprisingly Difficult Search for Anti-Vaccine Sentiments Online
}

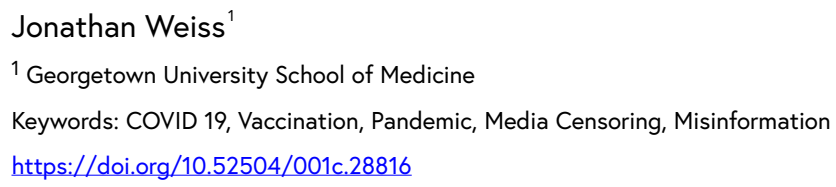

Georgetown Medical Review

Vol. 5, Issue 1, 2021

If you haven't done so already, consider attempting a Google search for COVID-19 anti-vaccine discourse, not because I want you to find inspiration in that direction, but because I invite you to step into the shoes of someone afflicted with what some politely call "vaccine hesitancy." I felt relief from completing the two-dose Pfizer vaccine and have become fascinated by those who might not have the same confidence in this feat of human engineering. Considering how widespread anti-vaccine attitudes are reported, I was surprised by the difficulty I had quenching my interest in learning about these perspectives.

At first, I attributed my failure to artless search terms: "vaccine bad," "harmful side effects covid vaccine," "don't take covid vaccine," "they won't tell you covid vaccine." The last search phrase excited me for a moment when, in 0.73 seconds, the top result yielded the article, Shocking truth about COVID-19 vaccination that the government won't tell you! ${ }^{1}$ but my hopes were quickly dashed when this turned out to be satire. The second result, What we're not telling the public when they get the vaccine, ${ }^{2}$ also had some initial promise. Sadly, this result turned out to be a reasonable concern, but not one that satisfied my search; written by an emergency physician, the article warns about the possibility of patients acquiring a SARS-CoV-2 infection in the week preceding their vaccinations, becoming sick, and attributing their illnesses to the vaccine. The rest of the results, including when I skipped through multiple pages of search results, included several articles housed in reputable sources that circled around themes of how to convince skeptics to see the light.

My failing search efforts, especially in the context of daily reminders about the existence of a large anti-vaccine movement, naturally made me question the transparency of Google's search engine. I became increasingly interested, and after a deep dive trying search terms that may have warranted incognito mode, I came face-to-face with my Moby: "TheDefender, Children's Health Defense News and Views." ${ }^{3}$ Less impassioned than Ahab, my reaction felt similar to when, as a young Jewish boy, I found the golden egg at a friend's Easter gathering: "Cool!" excited to accomplish a task, but not particularly connected with the prize. I wondered, however, how a devout skeptic might feel upon finding this needle in the haystack. 
TheDefender's website is designed with a crisp, professional quality and boasts that it is published in 5 languages. After spending a little time on the site, I learned that Robert F. Kennedy Jr. is the organization's Chairperson of the Board and Senior Prosecuting Attorney, who voices his passion for protecting children on a video message embedded on the front page. Some of the articles in the COVID section, such as Zogby Poll: 32\% Say Fauci Looking Out for Big Pharma, Not Public, ${ }^{4}$ seem to be written in bad faith, but others, like, Can Colleges and Employers Legally Require You to Get Vaccinated? It's Complicated, ${ }^{5}$ come across as reasonable attempts at journalism. Overall, TheDefender seems to value reporting claims that can be substantiated. While I disagree with the conclusions of these articles, I believe many of the authors raise understandable questions. The comment sections of these articles, on the other hand, are the Wild West of vaccine skepticism.

In these comment sections, I learned that the CDC stands for Criminal Disinformation Corp or "Center for Disease Control of which diseases they will impose on us each year. That is their control." I currently live in a neighborhood where about a quarter of the houses have "Thank you, Dr. Fauci" signs, so it was particularly incredible to contrast my world with the amount of disdain for Dr. Fauci that can be found on TheDefender. One commenter wrote of her impressive intuition: "The first time I saw Fauci... even before I understood who he was... I knew he was criminal... but now I understand he is much worse." ${ }^{4}$ Some commenters express their anger through humor and others simply express their anger, but many also express heartfelt concern and it's these I find to be the hardest to read. Within a conversation about the ethics of mandating college students to receive COVID-19 vaccines, one commenter shared, "I join in your heart break:(. I pray that something will cause the curtain to be pulled back on all the harm done... I pray one day we will read in history books about this dark age that disguised itself as progress and say 'never again."' This genuine feeling of fear was familiar to me, but in my world the fear was coming from my family and friends who worried about the consequences of people not getting the vaccine.

My search for the 'other side' was, ultimately, successful, but I don't know how I feel about my journey. Do I want anti-vaccine sentiments to be represented proportionally to their popularity? Am I comfortable with a heavy filter in our digital platforms? Some public health research suggests I'm not alone in my discomfort. ${ }^{7}$ As I see this situation, there are two layers of difficulty. One is woven in the fabric of our social media: dependent on an advertisement business model, tech companies compete for our attention and succeed by feeding our limbic systems with juicy confirmatory inputs, not maliciously, but still consequentially. I wonder if my search for anti-vaccine websites would have been easier if I had started with a different search history or even a different IP address. Social media's influence over our psyches is becoming an increasingly popular topic and is thoroughly explored in the film The Social Dilemma, 8 but while this influence may be the most crucial component in the divisiveness 
we've seen about vaccines and many other topics, I'm currently most intrigued by the genuine ambivalence I feel about the second layer of social media's role in our conversations: censorship.

There is a consensus within the scientific community that the COVID-19 vaccine is safe and effective. Yet some groups promote skepticism about the vaccine as well as scientific institutions themselves. To what degree is it reasonable for browser search algorithms to favor the scientific consensus over alternative perspectives? Censorship stories that I remember from high school history didn't end well, but I think we're currently presented with a different flavor of censorship than we have been in the past. The question is not whether anti-vaccine sources can be published online but to what degree technology corporations promote these sources' visibility through search results and recommendation newsfeeds.

Prior to the COVID-19 pandemic, tech companies were already grappling with the challenges of having anti-vaccine sources on their platforms. ${ }^{9}$ The major social media companies were being held partly responsible for decreases in childhood vaccination rates and, in response, began implementing strategies to better manage their influences over public health, such as de-prioritizing search results and removing access to some movies and books that were deemed to be 'misinformation.' ${ }^{9}$ Now, I wonder if the pendulum of these de-prioritization efforts has swung too far. We know some people will be seeking viewpoints that challenge scientific consensus and many of these people probably already have the news outlets that satisfy their opinions. Therefore, burying search results may motivate the skeptic's narrative more than it protects newcomers from encountering skeptic-driven information.

My initial voyage was on Google, but I've since tried a few other platforms and noticed a wide range of accessibility of sources that refute vaccine benefits. When searching "vaccine bad" on Bing, the first result for me was a 2017 article called 7 Reasons Why Vaccine Should Not Be Given! ${ }^{10}$ and the imperfect grammar in the title aligns nicely with its scientific reasoning about vaccines. The prominence of an article like this one makes me uncomfortable in the opposite direction as my Google search did and only adds doubt about what social media levers I would pull if I were in control.

Although I don't know a specific way forward, I have noticed an area in which we could probably do better. I rarely found articles or videos with contrasting opinions fairly represented within the same source, such as a reputable individual from the scientific community that endorses vaccines in conversation with a respected individual from a community that is distrustful of vaccines. In the time I've spent trying to understand vaccine hesitancy better, I initially noticed an 'othering' phenomenon in myself where I spontaneously put articles, authors, YouTubers, and commenters into either a pro- or anti-vaccine category. I then viewed that category as either with or against my viewpoint. This is satisfying. However, I've tried to combat this 
tendency and instead look for the feelings that motivate some of the ideas I disagree with and the end goals that the authors and commenters hold. As far as I can tell, most people on both sides of the vaccine coin share the same fears and goals, namely that people's lives are in danger and that most of us want to maximize public health. I truly believe these sentiments align across the aisle and that the main difference is how we believe we can optimize health. I also believe a supportive forum inviting varied viewpoints could help people communicate differences in a way that highlights similarities. If I'm wrong, however, there are some entertaining memes coming from both sides that we can enjoy as the harpoon sinks us both. 


\section{REFERENCES}

1. Whitmer L. Shocking truth about COVID-19 vaccination that the government won't tell you! Published online 2021. Accessed April 8, 2021. https://bucknellian.net/103898/satire/shockingtruth-about-covid-19-vaccination-that-the-government-wont-tell-you/

2. Faust J. What we're not telling the public when they get the vaccine. Intelligencer. Published 2021. Accessed April 8, 2021. https://nymag.com/intelligencer/2021/01/what-were-not-tellingthe-public-when-they-get-the-vaccine.html

3. Welcome to the defender. children's health defense. Accessed May 10, 2021. https://childrenshealthdefense.org/defender/welcome-to-the-defender/

4. Zogby poll: $32 \%$ say fauci looking out for big pharma, not public. children's health defense. Accessed April 8, 2021. https://childrenshealthdefense.org/defender/zogby-poll-fauci-big-pharma/

5. Redshaw M. Can colleges and employers legally require you to get vaccinated? it's complicated. children's health defense. Published 2021. Accessed May 10, 2021.

https://childrenshealthdefense.org/defender/can-colleges-employers-legally-require-vaccination/

6. Redshaw M. CDC changes rules for counting breakthrough cases, as more fully vaccinated people test positive. children's health defense. Published 2021. Accessed May 10, 2021.

https://childrenshealthdefense.org/defender/cdc-changes-rules-counting-breakthrough-cases/

7. Armitage R. Online 'anti-vax' campaigns and COVID-19: Censorship is not the solution. Public Health. 2021;190:e29-e30. doi:10.1016/j.puhe.2020.12.005

8. Orlowski J. The Social Dilemma. Netflix; 2020.

9. $20 \mathrm{CNM}, \mathrm{Am}$ 7. Tech's fight against anti-vaccine content prompts free speech debate. Accessed May 10, 2021. https://www.cbsnews.com/news/tech-companies-fight-against-vaccinemisinformation-prompts-free-speech-debate/

10. Vivek Areti S. 7 reasons why vaccine should not be given! Accessed May 10, 2021. https://www.practo.com/healthfeed/7-reasons-why-vaccine-should-not-be-given-30705/post 